\title{
3 Research Square

\section{Zoonotic Trematode Prevalence In Galba Pervia (Lymnaeidae) And Experimental Infection Of Three Isolated Trematodes In The Intestine Of Duck}

Jian Li

Guangxi Traditional Chinese Medical University

Yijing Ren

Guangxi University

Lei Yang

Guangxi University

Jiani Guo

Guangxi University

\section{Haiying Chen}

Inner Mongolia University

Jiani Liu

Inner Mongolia University

Haoqiang Tian

Inner Mongolia University

Qingan Zhou

Guangxi University

Weiyi Huang

Guangxi University

Wei Hu

Inner Mongolia University

Xinyu Feng ( $\sim$ fengxinyu2013@163.com )

Inner Mongolia University https://orcid.org/0000-0002-4120-7759

\section{Research Article}

Keywords: Galba pervia, Trematode, Intermediate host, Echinostoma, Fasciola, ITS-2

Posted Date: February 10th, 2022

DOI: https://doi.org/10.21203/rs.3.rs-1327887/v1 
License: (c) (i) This work is licensed under a Creative Commons Attribution 4.0 International License. Read Full License 


\section{Abstract}

Background: Food-borne diseases cause serious harm to public health and food safety. The snail species Galba pervia is an intermediate host for an array of parasitic trematodes. In this study, we performed a prevalence investigation on zoonotic trematode in G. pervia in Guangxi, China, and assessed the zoonotic potential of Trematode in the region.

Methods: G. pervia was collected from 61 sites in 9 cities throughout Guangxi Provinces between 2012 to 2014. The larvae species were determined by combing morphological and molecular characteristics. Phylogenetic trees were constructed using neighbor-joining method with ITS2 sequences. The developmental cycles of the isolated trematodes were examined by experimental infection in ducks. The developmental characteristics of Echinostoma revolutum was recorded by dissecting infected ducklings from $1 \mathrm{dpi}$ to $10 \mathrm{dpi}$.

Results: Species identification showed E. revolutum, Australapatemon sp., Hypoderaeum conoideum, Pharyngostomum cordatum and Echinostoma sp. parasitized in G. pervia. However, no Fasciola larvae had been detected. A Neighbor-Joining tree analysis of ITS2 sequences resulted in monophyletic clades comprised of all sequences from isolated larvae with high bootstrap support. The overall prevalence of Trematode larvae in G. pervia was $22.0 \%$ (1818/8258), while E. revolutum presented with the highest infection rate of $12.9 \%$ from 11 sampling sites. Ducklings exposed to Echinostoma sp., E. revolutum, and H. conoideum larvae were successfully infected. E. revolutum larvae matured at $10 \mathrm{dpi}$ in the intestine of the duck, and the developmental characteristics of E. revolutum were characterized by the maturation of the reproductive and digestive organs around $6 \sim 8 \mathrm{dpi}$.

Conclusions: The present investigation revealed the high prevalence of trematodes in the G. pervia in Guangxi, China. With existing trematode infection human cases together with wide geographical distribution of G. pervia, more insight into the risks of human health and its link to human infections are needed.

\section{Background}

Food-borne trematode is a parasitic disease that seriously harms humans and animals [1,2,3]. Common food-borne fluke disease are fasciolosis, paragonimosis, schistosomatosis, gastrodiscosis, etc. Corresponding pathogens include fasciolidae, echinostomatidae, opisthorchiidae, heterophyidae, etc[3, 4, 5]. Food-borne trematodes can infect a wide range of mammals, including livestock and humans, causing severe veterinary and public health problems worldwide [6, 7]. Although the infection rates are low, several outbreaks have been reported recently $[8,9]$.

Galba pervia belongs to Mollusca, Gastropoda, Pulmonata, Basommatophora, Lymnaeidae, Galba [10]. It is an intermediate host for a variety of trematodes, some of which are zoonotic, such as F. gigantica, $F$. hepatica, Echinostoma revolutum, Echinochasmus perfoliatus and plays a vital role in the transmission and prevalence of these diseases [11]. The shell of G. pervia is thin and translucent with an ear-shaped 
aperture; the ratio apex/body is $10 / 8 \mathrm{~mm}$. Its natural habitats ranged from lakes, canals, ponds, and rice fields. Oviparous hermaphroditic $G$. pervia lives in large aggregation in suitable environments such as sewage sludge bottom or broken bricks and feeds on algae, hummus, and aquatic plants [12]. G. pervia is widely distributed in China and is the dominant host snail for transmitting Fasciola spp [13].

Food-borne trematode is often infected by eating raw vegetables such as fish mint (Houttuynia cordata), lettuce (Lactuca sativa), parsley (Petroselinum crispum), and watercress (Nasturtium officinale) [14]. From 2011 to 2012, there was an outbreak of F. gigantica infection in Binchuan County, Dali Prefecture, Yunnan Province in China, and then the authors think that fish mint was most likely the source of diseases $[9,15]$. Guangxi Zhuang Autonomous Region is contiguous to Yunnan and shares a similar climate, as well as lifestyles and dietary habits of the local people. Given that the Galba pervia is the important intermediate host of Fasciola in China $[11,16]$, it also has a wide distribution in Guangxi, representing a potential risk of parasitic zoonosis. Therefore, the main objective of this study was to investigate and identify presence of various trematode larvae in G. pervia in Guangxi, and assess the zoonotic potential of trematode for both animal and human in this area.

\section{Methods}

\section{Study areas and snail collection}

To investigate the potential vector capacity of G. pervia in Guangxi Province, snails were collected from 54 sites in 9 cities, namely, Beihai, Fangchenggang, Guigang, Guilin, Liuzhou, Laibin, Nanning, Qinzhou, Wuzhou, and Yulin, from 2012 August to 2014 August (the number of snail samples per site was about 200). Two types of areas were included: Type 1 areas were rice cultivation areas (contains 51 sites, marked by circular shapes in Fig. 1G); Type 2 areas were the vegetation areas of crops which often used as the raw food (10 sites, marked by triangular shape in Fig. 1G). Details of each locality sampled are given in Table S1. In each sampling site, the snails were collected manually by the plastic scoop, transported to the laboratory, cleaned and rinsed five times in sterilized water, and then placed in plastic trays for subsequent experiments.

\section{Fig. 1}

\section{Identification of snails and isolation of trematodes larvae}

The snails were identified morphologically as G. pervia depending on systematic keys of the shell [12]. Then collected G. pervia were dissected under a stereomicroscope and carefully checked for trematodes larvae (rediae, cercariae, or metacercariae), and the larvae were separated from the tissue. We used MoticBA400 microscope to observe and record the body length and body width of each isolated trematode. The body length and body width of rediae, and the body length, body width, tail long and tail width of cercariae at each site were measured. The diameter and wall thickness of metacercaria were also measured. 


\section{Molecular examinations of the trematodes}

Next, a single larva with the identical morphology at each sampling site was selected and rinsed with sterilized distilled water three times before being used to extract parasite genomic DNA by a DNeasy Blood \& Tissue kit (Qiagen, Hilden, Germany) according to the manufacturer's instructions. The extracted DNA samples were stored at $-20^{\circ} \mathrm{C}$ until PCR amplification. The PCR assay targeting the sequence of the internal transcribed spacer 2 (ITS2) gene was used to amplify trematode larvae. The universal primer pairs were designed as described by McManus et al. [17]. All the PCR products were directly sequenced after being purified. The obtained sequences were edited using DNASTAR software (www.dnastar.com/software/lasergene/) and aligned using ClustalX (http://www.clustal.org/clustal2/). The identity of individual specimens was ascertained by comparison with the sequences available in 'non-redundant' database in GenBank by BLAST (http://www.ncbi.nlm.nih.gov/blast/). The nucleotide sequences obtained in the present study have been deposited in the GenBank database under the accession numbers.

\section{Phylogenetic tree construction with ITS2}

Phylogenetic trees were constructed using the neighbor joining ( $N J$ ) method in MEGAX (26). The $F$. gigantica (MK321643), isolated from a cattle, was used as an out-group for the construction of the phylogenetic trees of Echinostoma sp. (KJ848453, KJ848454, and KJ848455), E. revolutum (AY168930, KM980474, KM980476 and KM980477), H. conoideum (AJ564385, KJ944311, KJ944312, and KJ944313), E. robustum (LC224084), E. friedi (AJ564383), E. miyagawai (MW199188), E. paraensei (AF336232), E. caproni (AJ564382), E. trivolvis (GQ463127), E. malayanum (JF412727), and Echinoparyphium recurvatum (AY168931 and KJ435270). For the construction of phylogenetic tree of Australapatemon sp. (KM980467, KM980468, KM980469, KM980470, and KM980471), Pharyngostomum cordatum (OL870492 and KJ137231), A. burti (KU950451), Austrodiplostomum ostrowskiae (KT72878), Alaria americana (MH521246), Diplostomum paracaudum (KJ889013) and Cyathocotyle prussica (MH521249), the Brachylaima sp. (JX010634) and Schistosoma japonicum (S72866) were used as out-groups. The phylogeny was tested with 1,000 bootstrap replicates, using the Kimura two-parameter model as a nucleotide substitution model and gamma distribution as rates among sites.

\section{Experimental infections of isolated trematodes in the intestine of duck}

Five-day-old ducklings were fed with snails parasitized by isolated trematodes in the field. Each duckling was fed $20 \mathrm{G}$. pervia, and one duckling was dissected every day from the 1 st to 10 th day after ingestion. The trematodes were collected from the duck intestines using a complete helminthological dissection method [5], and high-resolution pictures of the collected trematodes were taken with the Motic BA400 microscope and additional accessories. The carmine staining of the press-and-fixed specimen was made according to the method provided by Kong Fanyao [6], and collar, spines, oral sucker, acetabulum, prepharynx, esophagus, testis, ovary was measured from digital images during daily observations. In addition, a single trematode was selected, and a small amount of tissue from the tail of the parasite was 
cut out aseptically. After repeated rinsing with sterilized distilled water 2-3 times, DNA extraction was carried out according to the above method. ITS2 gene was amplified and sequenced using the same method, and the trematode species was verified.

\section{Results}

\section{Overall information on the sampling and survey data}

G. pervia samples were collected from 54 sites (as shown in Fig. 1G) with about 38-214 snails in each site. Trematodes were found in 17 sites investigated following dissection, including Tianbao Reservoir and Hede village in Nanning city, Liushan Town, Liutang Village, Guangrong village, and Cha Village in Liuzhou City, and Maling Town in Guilin City. Various stages in the life history of this trematode (redia, cercaria and metacercariae) were found during dissection procedures.

\section{Morphological characters and molecular identification of trematodes larvae}

The rediae of echinostomes were cylindrical, blunt at both ends, slightly pointed at the head and more pointed at the tail. The body was curved to the ventral surface with muscular feet, and the movement was slow. The tail of the cercariae is not forked. The head of $H$. conoideum cercariae shows prominent spines, as well as well-developed ventral suckers, pharynx, and intestines (Fig. 2D-F). The metacercaria were round and have two transparent walls (the outer wall was thicker than the inner wall). Abdominal suckers and refractive granules of larvae could be seen inside the cyst. Due to the movement of the larvae inside the sac, the small spines around its head were not easily observed. The rediae of Australapatemon sp. forms a distinct bulge at the head. The cercaria larvae had a forked tail, which was obviously longer than the body length. The cercaria of $P$. cordatum also had visible forked-tail, oral sucker and pharynx (Fig. 2JL).

Figure 2

Based on morphologically available keys, the species of isolated trematodes were identified by amplification of ITS2 region and verified through BLAST (blast.ncbi.nIm.nih.gov/Blast.cgi) with the highest identity after sequencing. Finally, we identified five different species of trematodes including Australapatemon sp., Echinostoma sp., E. revolutum, H. conoideum, and P. cordatum. The lengths of ITS2 were 292 bp, 429bp, 430bp, 432 bp and 294 bp, respectively. The nucleotide sequences obtained in the present study have been deposited in GenBank database under the accession numbers KM980466KM980471 (Australapatemon sp.), KJ848453-KJ848455 (Echinostoma sp.), KM980474 and KM980476KM980477 (E. revolutum), KJ944311-KJ944313 (H. conoideum) and OL870492 (P. cordatum).

The prevalence of trematodes in G. pervia

The overall trematodes infection rate was 22.0\% (1818/8258). Echinostoma revolutum were detected in the snails from 11 sampling sites, with an infection rate of 12.9\% (1069/8258); Hypoderaum conoideum infection was detected in the snails from two sampling sites, with an average infection rate of $3.8 \%$ 
(315/8258). Infection of Australapatemon sp. was detected in the snails form 2 sampling sites, with an infection rate of 2.5\% (206/8258); Infection of Pharyngostomum cordatum and Echinostoma sp. were detected at 1 sampling site with an infection rate of $0.4 \%$ (34/112) and 2.3\% (194/8258), respectively.

\section{Phylogenetic analyses}

In total, 15 representative high-quality ITS2 sequence data was obtained. Figure 2 shows an NJ tree based on the submitted sequences and relevant GenBank sequences. The ITS2 sequences of Echinostoma sp. constituted a monophyletic clade (Fig. 3A shaded pink area), distinct from the clade formed by E. robustum, E. friedi and E. miyagawai. The sequences of E. revolutum and $H$. conoideum constituted a monophyletic group together with E. revolutum (AY168930) and H. conoideum (AJ564385) references (Fig. 3A shaded blue area). The ITS2 sequences of Australapatemon sp. formed a group with A. burti (KU950451) at $99 \%$ bootstrap value but formed a unique clade at $75 \%$ bootstrap value. Figure 3B showed that the ITS2 sequences of $P$. cordatum were identical to the reference sequences of $P$. cordatum (KJ137231).

Figure 3

Laboratory infection experiment with Echinostoma sp., E. revolutum, and H. conoideum

Because there was no suitable second intermediate host for $P$. cordatum and definitive host for Australapatemon sp., we conducted an infection experiment for isolated three kinds of trematode to evaluate rates of parasite establishment in ducklings. Ducklings were individually exposed to Echinostoma sp., E. revolutum, and $H$. conoideum larvae and all were successfully infected. Subsequent observation on Ducklings (17 dpi) fed with Echinostoma sp. infected G. pervia, we detected eggs $(195.8 \times 143.8 \mu \mathrm{m})$ in the feces, and the morphological characteristics of adult Echinostoma sp. were presented as measures: body length $9.8 \mathrm{~mm}$, width $1.2 \mathrm{~mm}$, oral suker $638.9 \times 399.2 \mu \mathrm{m}$, acetabulum 1591.2×1338.2 $\mu \mathrm{m}$, pharynx $492.6 \times 331.7 \mu \mathrm{m}$, anterior testis $1120.5 \times 707.4 \mu \mathrm{m}$, posterior testis $1274.9 \times 880.4 \mu \mathrm{m}$, ovary $818.9 \times 527.9 \mu \mathrm{m}$. In contrast, we found $H$. conoideum eggs in ducklings fed with infected G. pervia from three sites from a median of $12 \mathrm{dpi}$ (range: $9 \mathrm{dpi}$ to $14 \mathrm{dpi}$ ). The morphological characteristics of adult $H$. conoideum were: body length $1.05 \mathrm{~mm}$, width $1.5 \mathrm{~mm}$, oral suker $424.2 \times 293$ $\mu \mathrm{m}$, acetabulum $1610.2 \times 1594.6 \mu \mathrm{m}$, pharynx $379.8 \times 253.6 \mu \mathrm{m}$, anterior testis $1902.6 \times 875.3 \mu \mathrm{m}$, posterior testis $2045.2 \times 898.2 \mu \mathrm{m}$, ovary $751.7 \times 553.9 \mu \mathrm{m}$, and also characterized by the possession of 50 spines. E. revolutum eggs $(104.1 \times 63.1 \mu \mathrm{m})$ were found on $10 \mathrm{dpi}$. The morphology of adult $E$. revolutum was characterized by: body length $8.5 \mathrm{~mm}$, width $2.2 \mathrm{~mm}$, oral suker $260 \times 180.1 \mu \mathrm{m}$, acetabulum $741.6 \times 598.3$ $\mu \mathrm{m}$, pharynx $193.1 \times 150.6 \mu \mathrm{m}$, anterior testis $628 \times 459.4 \mu \mathrm{m}$, posterior testis $725.5 \times 557.9 \mu \mathrm{m}$, ovary $411.8 \times 311.2 \mu \mathrm{m}$, and presence of a head collar with 37 spines.

The developmental characteristics of E. revolutum in duckling host from juvenile to adult

As there were not sufficient metacercariae of other trematodes, experiments were only designed to gain insight into how $E$. revolutum developed in duckling hosts. The developmental characteristics of $E$. 
revolutum was recorded by dissecting infected ducklings from $1 \mathrm{dpi}$ to $10 \mathrm{dpi}$ (eggs in the feces were first detected). E. revolutum could be obtained in the small intestine from 1 to $7 \mathrm{dpi}$ and then migrate and reside in the cecum and colon around 8-10 dpi. The body length developed from $490 \mu \mathrm{m}$ to $8500.5 \mu \mathrm{m}$ (a dramatic 17 -fold increase). At $1 \mathrm{dpi}$, juveniles presented a circumoral collar bearing 37 spines in a double circle and characterized by clearly visible oral suckers, acetabulum, pharynx, esophagus, and cecum. At 1 $\mathrm{dpi}$, the tiny structure of the testis appeared. By $4 \mathrm{dpi}$, the ovaries were beginning to organize and develop, and the seminal receptacle began to form. The tubular-shaped uterus loomed at $4 \mathrm{dpi}$, and maturation of the reproductive and digestive organs occurred around $6 \sim 8 \mathrm{dpi}$. The vitelline glands were the last to appear, and several eggs deposited in the uterus could be observed at 9 dpi. E. revolutum larvae matured at $10 \mathrm{dpi}$ and excreted eggs (Fig. 4). The daily measurement of E. revolutum development was recorded in detail, as shown in Table S2.

Figure 4

\section{Discussion}

Numerous species of food-borne trematodes are endemic in developing nations and significantly impact public health $[18,19,20]$. Austropeplea, Galba, Lymnaea, Radix and Stagnicola etc. from the families Lymnaeidae act as intermediate hosts of trematodes with substantial implications for human health [10, 13]. The primary research focused on the capability of transmitting Fasciola sp., and at least 20 species of Lymnaeidae have been described as potential vectors of fascioliasis [21]. The results reported in the present paper demonstrate the presence of five trematode species in G. pervia. Morphological characteristics identified the larvae to species level by combining unequivocal molecular markers, which identified as E. revolutum; $H$. conoideum; Australapatemon sp. P. cordatum and Echinostoma sp., respectively. Different collection sites differed concerning the larvae species and intensity of snails present, which would link with meteorological parameters and habitat types.

However, other trematode fauna, such as Fasciola, has not been detected, although Guangxi is one of the important regions of ruminant fascioliasis prevalence in the previous reports [22]. Our investigation indicated that $E$. revolutum was the most prevalent trematode species in Guangxi Province, with an infection rate of $12.9 \%$ among collected snails. In consideration of previous studies that Echinostomatidae have low intermediate host specificity [23]. In addition, Radix plicatula, R. swihoei, Gyraulus conrexiusculus etc. can also act as intermediate hosts [24], and all of above-mentioned snail species also have a wide distribution in Guangxi Province, so it implicates that the actual infection rate of Echinostomatidae trematodes may be much higher than the results found in this study.

There are many species of echinostomes, which are tiny parasites that mainly parasitize the intestines of birds, mammals, and humans $[21,25,26]$. However, due to the high diversity of species and similar morphology, some species have not been fully morphologically described by the most used morphological traits, with a precise classification elusive. In addition, it is time-consuming to identify the adults by reintroducing the larvae to complete their life cycles, and the improper selection of the definitive 
experimental host will also lead to the failure of entering the next stage of the life cycle. Given these facts, Jonsson et al. proposed to apply gene markers or restriction fragment length polymorphism (RFLP) for molecular identification [17, 21, 27, 28]. ITS2 species-specific markers have been proven as suitable genetic markers for identifying and differentiating trematode species. Because the external morphology of trematode metacercariae from this study was quite similar, the ITS2 gene sequences of metacercariae were amplified to identify the metacercariae. The species identification results are consistent with morphological analyses, and the evolutionary relationships of trematode species were successfully elucidated and compared with reference sequences deposited in the public databases.

As early as 1968, Lie [29] et al. proposed that the development of trematodes may be restricted by others due to the competition inside the snail when they take the same species of snail as the intermediate host. Subsequent studies revealed a similar competition relationship in the intermediate host of echinostomes [30] and schistosomes [31]. In our study, different trematode species have not been detected in one snail simultaneously. Meanwhile, although $G$. pervia snail can also serve as the intermediate host for Fasciola in Guangxi Province, we have not observed Fasciola infected G. pervia. This phenomenon may be caused by the cross-species competitive antagonisms of echinostomes with other trematodes, which led to a generally low or non-infection of Fasciola. Trematode is a parasite that can cause severe zoonotic diseases. Lie proposed that the transmission of the disease could be contaminated through competition among trematode larvae in intermediate hosts in 1973 [32]. Although theoretically, echinostomes could be used to reduce the economic losses caused by Fasciola, however, given its great harm to the livestock and poultry, echinostomes are not sound biological control agents for the control of Fasciola in practice. To unveil the trematode infection rate in larger areas in Guangxi Province, it is necessary to expand the sampling sites and select more species of snails for investigation. Further research is needed to determine the coexistence and coevolution of competitive species, especially two or more trematodes that reside in one snail host in natural communities.

Echinostomes are a common intestinal parasitic trematode in poultry, which mainly affects the growth and development of the young while is less harmful to the adult. The developmental cycle of echinostomes in its terminal host is short and uncomplicated. Therefore, the animal developmental model of the echinostomes in its terminal host is suitable for studying the immune response between trematode and its host. The research results can also be used as a reference for other small intestinal flukes which induce the terminal host immune response, and related research has also been reported in recent years [3-4]. This study is mainly aimed at the observation of the growth and development of echinostomes from decapsulation of the cyst to the sexually mature adult stage in the intestinal tract of the terminal host. For the selection of experimental animals, mammals are not susceptible to echinostomes infection, so ducklings were used as the definitive host in our study. To provide a basis for subsequent related research, it needs to explore more animal models for echinostomes infection in the future.

\section{Conclusions}


The present investigation revealed the prevalence of five trematodes species in the G. pervia in Guangxi Province, China. The results from our study not only provide a baseline information but also offered laboratory experimental models for assessing the potential zoonotic echinostomiasis from G. pervia. Further research is needed toward the understanding risk of human infection in combination with risk evaluation to ameliorate unwanted adverse effect during casual contact or exposure to infected G. pervia.

\section{Declarations}

\section{Ethics approval and consent to participate}

Not applicable

\section{Consent for publication}

All participants consented to have their data published.

\section{Availability of data and materials}

The sequences data has already submitted to GenBank, and will be released to the public database until Dec 1, 2016. The GenBank accession numbers are KX781395 for the ITS2 of Australapatemon sp., KM980463 KM980465, KM980478 KM980479 for the Hypoderaeum conoideum, KM980474 and KM980476 KM980477 for the Echinostoma revolutum.

\section{Competing interests}

The authors declare that they have no competing interests.

\section{Funding}

This study was supported by the Guangxi Traditional Chinese Medical University Scientific Research Project (XP021059); National Parasitic Resources Center (NPRC-2019-194-30); Key Technology Project of Inner Mongolia Science and Technology Department (2021GG0171).

\section{Authors' Contributors}

LJ and RYJ conceived and designed the study. LJ, RYJ, LY, GJN and CHY, LJN, THQ, ZQA and HWY collected and identified the snails, cercariae and metacercariae. RYJ and LJ analyzed the data and drafted the manuscript. LJ, FXY and HW helped in study design, study implementation and manuscript revision. LJ, FXY and HW critically revised the manuscript. All authors read and approved the final manuscript.

\section{Acknowledgments}

Not applicable 


\section{References}

1. Leonardo L, Hernandez L, Magturo TC, Palasi W, Rubite JM, de Cadiz A, et al. Current status of neglected tropical diseases (NTDs) in the Philippines. Acta Trop. 2020;203:105284. doi:10.1016/j.actatropica.2019.105284.

2. Li L, Liu X, Zhou B, Zhang S, Wang G, Ma G, et al. Multiple food-borne trematodiases with profound systemic involvement: a case report and literature review. BMC Infect Dis. 2019;19 1:526; doi:10.1186/s12879-019-4140-y.

3. Keiser J, Utzinger J. Food-borne trematodiases. Clin Microbiol Rev. 2009;22 3:466-83. doi:10.1128/cmr.00012-09.

4. Mas-Coma S, Bargues MD, Valero MA. Human fascioliasis infection sources, their diversity, incidence factors, analytical methods and prevention measures. Parasitology. 2018;145 13:1665-99. doi:10.1017/s0031182018000914.

5. Mohanta UK, Watanabe T, Anisuzzaman, Ohari Y, Itagaki T. Characterization of Echinostoma revolutum and Echinostoma robustum from ducks in Bangladesh based on morphology, nuclear ribosomal ITS2 and mitochondrial nad1 sequences. Parasitol Int. 2019;69:1-7; doi:10.1016/j.parint.2018.11.002. https://www.ncbi.nlm.nih.gov/pubmed/30445199.

6. Bhutta ZA, Sommerfeld J, Lassi ZS, Salam RA, Das JK. Global burden, distribution, and interventions for infectious diseases of poverty. Infect Dis poverty. 2014;3 1:21; doi: 10.1186/2049-9957-3-21. https://doi.org/10.1186/2049-9957-3-21.

7. Rondelaud D, Vignoles P, Dreyfuss G. Larval trematode infections in Galba truncatula (Gastropoda, Lymnaeidae) from the Brenne Regional Natural Park, central France. J Helminthol 2016;90 3:256-61; doi:10.1017/S0022149X15000073. https://www.ncbi.nlm.nih.gov/pubmed/25804319.

8. Wang J-L, Li T-T, Huang S-Y, Cong W, Zhu X-Q. Major parasitic diseases of poverty in mainland China: perspectives for better control. Infect Dis poverty. 2016;5 1:67; doi:10.1186/s40249-016-0159-0. https://doi.org/10.1186/s40249-016-0159-0.

9. Chen JX, Chen MX, Ai L, Xu XN, Jiao JM, Zhu TJ, et al. An Outbreak of Human Fascioliasis gigantica in Southwest China. PLoS One 2013;8 8:e71520; doi:10.1371/journal.pone.0071520. https://www.ncbi.nlm.nih.gov/pubmed/23951181.

10. Malek EA. Snail-Transmitted Parasitic Diseases: Volume II. CRC Press; 2018.

11. Liu GH, Wang SY, Huang WY, Zhao GH, Wei SJ, Song HQ, et al. The complete mitochondrial genome of Galba pervia (Gastropoda: Mollusca), an intermediate host snail of Fasciola spp. PLoS One 2012;7 7:e42172; doi:10.1371/journal.pone.0042172.

https://www.ncbi.nlm.nih.gov/pubmed/22844544.

12. Liu Y. Medical Malacology (In Chinese). China Ocean Press. 1993;:68-9.

13. Lu XT, Gu QY, Limpanont Y, Song LG, Wu ZD, Okanurak K, et al. Snail-borne parasitic diseases: an update on global epidemiological distribution, transmission interruption and control methods. Infect Dis poverty. 2018;7 1:28; doi:10.1186/s40249-018-0414-7. 
14. Rim H-J, Farag HF, Sornmani S, Cross JH. Food-borne trematodes: Ignored or emerging? Parasitol Today. 1994;10:207-9.

15. Chen JX, Chen MX, Ai L, Xu XN, Jiao JM, Zhu TJ, et al. An Outbreak of Human Fascioliasis gigantica in Southwest China. Plos One. 2013;8:8:e71520.

16. Zhang HYKF, Shen YL, Gu YF, Shen T. Detection of Fasciola hepatica in galba pervia by dot hybridization. Chin j vet parastiol. 1999;1:1-3; doi:10.1016/j.exppara.2009.08.014. http://www.ncbi.nlm.nih.gov/pubmed/19723524.

17. McManus D, Bowles J. Molecular genetic approaches to parasite identification: their value in diagnostic parasitology and systematics. Int J Parasitol. 1996;26 7:687-704.

18. Chai JY, Sohn WM, Na BK, Nguyen VD. Echinostoma revolutum: metacercariae in Filopaludina snails from Nam Dinh Province, Vietnam, and adults from experimental hamsters. Korean J Parasitol 2011;49 4:449-55; doi:10.3347/kjp.2011.49.4.449. https://www.ncbi.nlm.nih.gov/pubmed/22355218.

19. Sohn WM, Chai JY, Yong TS, Eom KS, Yoon CH, Sinuon M, et al. Echinostoma revolutum infection in children, Pursat Province, Cambodia. Emerg Infect Dis 2011;17 1:117-9; doi:10.3201/eid1701.100920. https://www.ncbi.nlm.nih.gov/pubmed/21192870.

20. Chai JY, Sohn WM, Yong TS, Eom KS, Min DY, Hoang EH, et al. Echinostome flukes receovered from humans in Khammouane Province, Lao PDR. Korean. J Parasitol 2012;50 3:269-72; doi:10.3347/kjp.2012.50.3.269. https://www.ncbi.nlm.nih.gov/pubmed/22949759.

21. Correa AC, Escobar JS, Durand P, Renaud F, David P, Jarne P, et al. Bridging gaps in the molecular phylogeny of the Lymnaeidae (Gastropoda: Pulmonata), vectors of Fascioliasis. BMC Evol Biol 2010;10:381; doi:10.1186/1471-2148-10-381. https://www.ncbi.nlm.nih.gov/pubmed/21143890.

22. Dongying Wang WZ, Weiyi Huang. The epidemiology investigation of Fasciola spp. in Guangxi, China (In Chinese). Guangxi J Anim Husb Veterinary Med. 2006;22 5:200-2.

23. Munoz-Antoli C, Trelis M, Toledo R, Esteban JG. Infectivity of Echinostoma friedi miracidia to different snail species under experimental conditions. J Helminthol. 2006;80 3:323-5. http://www.ncbi.nlm.nih.gov/pubmed/16923279.

24. Chen Yuan-xiao, Tian ZW, Ming. Chen Ying-jie, Wang Wen-lin, Zhang Nai-guang. Investigation of snails transmitting parasitic diseases in Yunnan Province (in Chinese). J Pathogen Biology. 2009;4(3):211-4.

25. Hussein A, Califa R, Mas-Coma S. Trematode larval stages infecting Radix natalensis (Gastropoda: Lymnaeidae) in Qena Governorate, Egypt, with special reference to fasciolid cercariae. Res Rev Parasitol. 2005;66(1-4):69-74.

26. Anh NTL, Madsen H, Dalsgaard A, Phuong NT, Thanh DTH, Murrell KD. Poultry as reservoir hosts for fishborne zoonotic trematodes in Vietnamese fish farms. Vet Parasitol. 2010;169(3-4):391-4.

27. Wiroonpan $P$, Chontananarth $T$, Purivirojkul W. Cercarial trematodes in freshwater snails from Bangkok, Thailand: prevalence, morphological and molecular studies and human parasite 
perspective. Parasitology 2021;148 3:366-83; doi:10.1017/S0031182020002073.

https://www.ncbi.nlm.nih.gov/pubmed/33100233.

28. Jousson O, Bartoli P, Pawlowski J. Molecular identification of developmental stages in Opecoelidae (Digenea). Int J Parasitol. 1999;29 11:1853-8. doi:10.1016/s0020-7519(99)00124-1.

29. Lie KJ, Basch PF, Heyneman D, Beck AJ, Audy JR. Implications for trematode control of interspecific larval antagonism within snail hosts. Trans R Soc Trop Med Hyg. 1968;62 3:299-319. doi:10.1016/0035-9203(68)90081-3.

30. Joe LK, Basch PF, Heyneman D, Fitzgerald F. Antagonism between two species of echinostomes (Paryphostomum segregatum and Echinostoma lindoense) in the snail Biomphalaria glabrata. Z Parasitenkd. 1968;30(2):117-25. doi:10.1007/bf00259720.

31. Lie KJ: A possible biological control of schistosomiasis and other trematodes in snails. In: Southeast Asian Seminar on Parasitology \& Tropical Medicine, Schistosomiasis \& other Snail-transmitted Helminthiasis (4th), Manila, Feb 24-27 1969 Proceedings1969: 131-8.

32. Lie KJJEP. Larval trematode antagonism: principles and possible application as a control method. 1973;33 2:343-9.

\section{Figures}




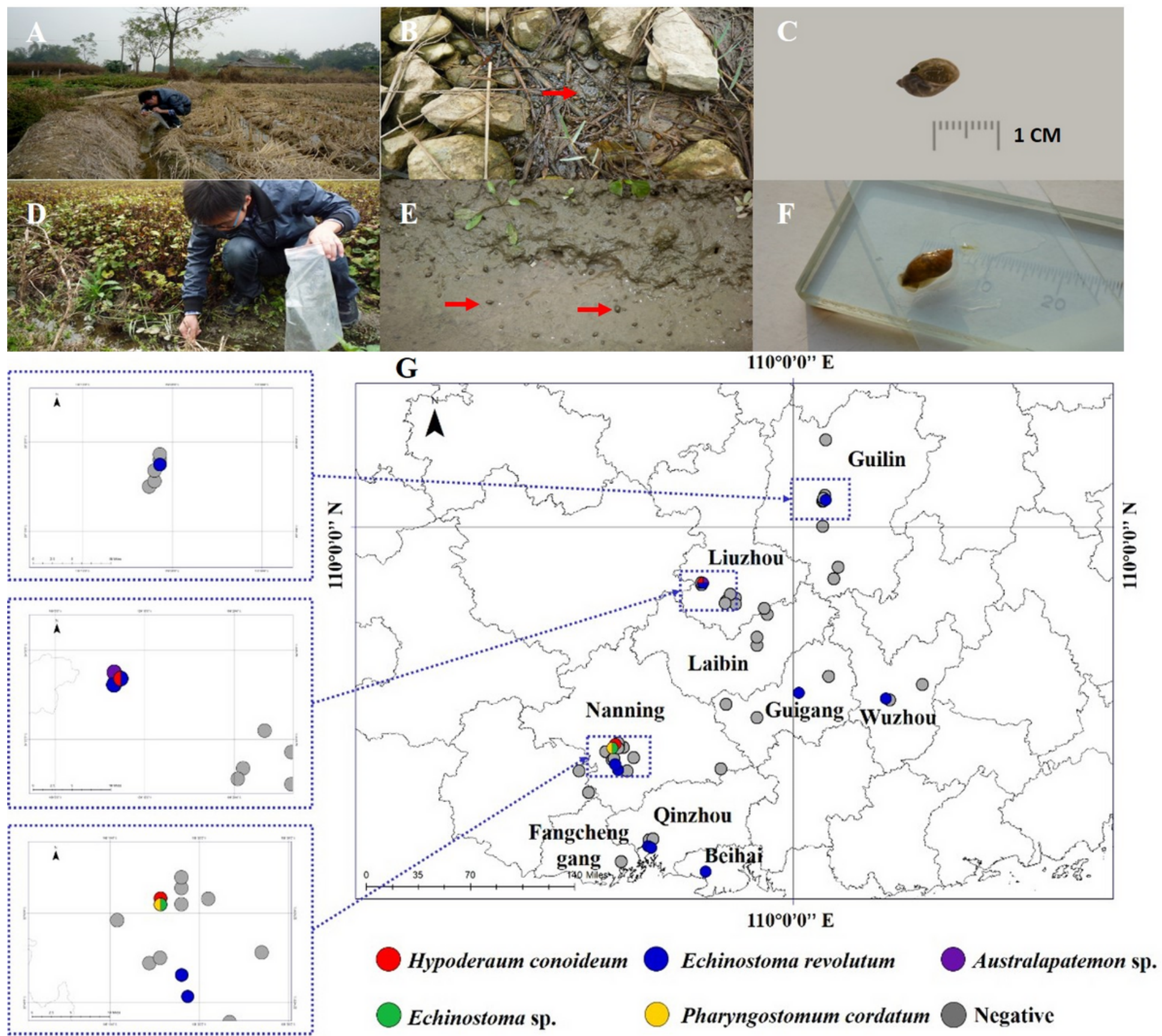

Figure 1

A, B: Type 1 areas were rice cultivation areas; C: G. pervia image in anterior view; D, E: Type 2 areas were the vegetation areas of agricultural crops which often used as the raw food; $F$ : $G$. pervia image posterior view; G: 54 G. pervia snail collection sites in 9 cities in Guangxi Province. 


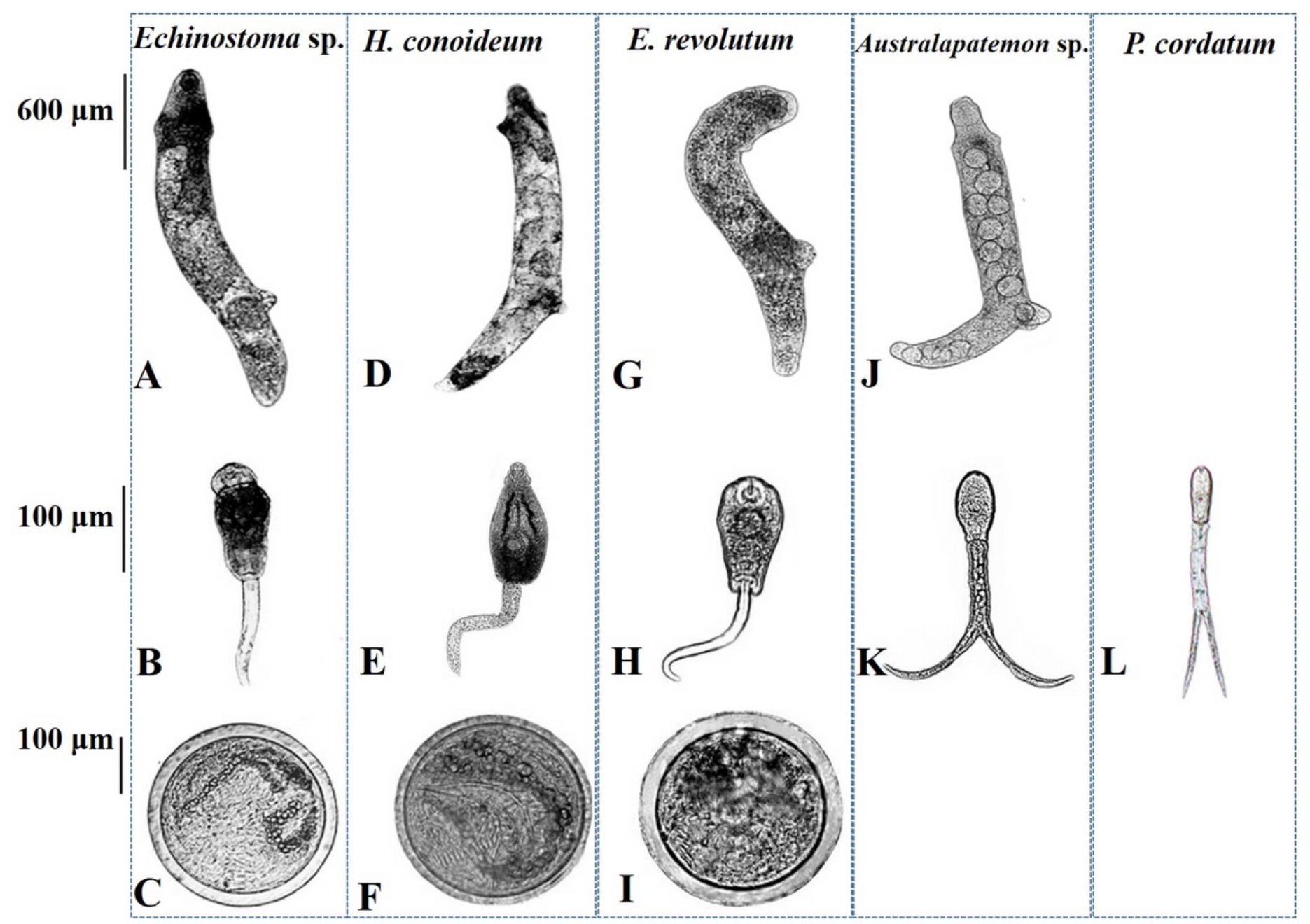

Figure 2

Morphology of rediae, cercariae and metacercariae collected in G. pervia. A-C: The rediae, cercariae and metacercariae of Echinostoma sp.; D-F: The rediae, cercariae and metacercariae of Hypoderaeum conoideum; G-I: The rediae, cercariae and metacercariae of Echinostoma revolutum; J, K: The rediae and cercariae of Australapatemon sp.; L: The cercariae of Pharyngostomum cordatum. 

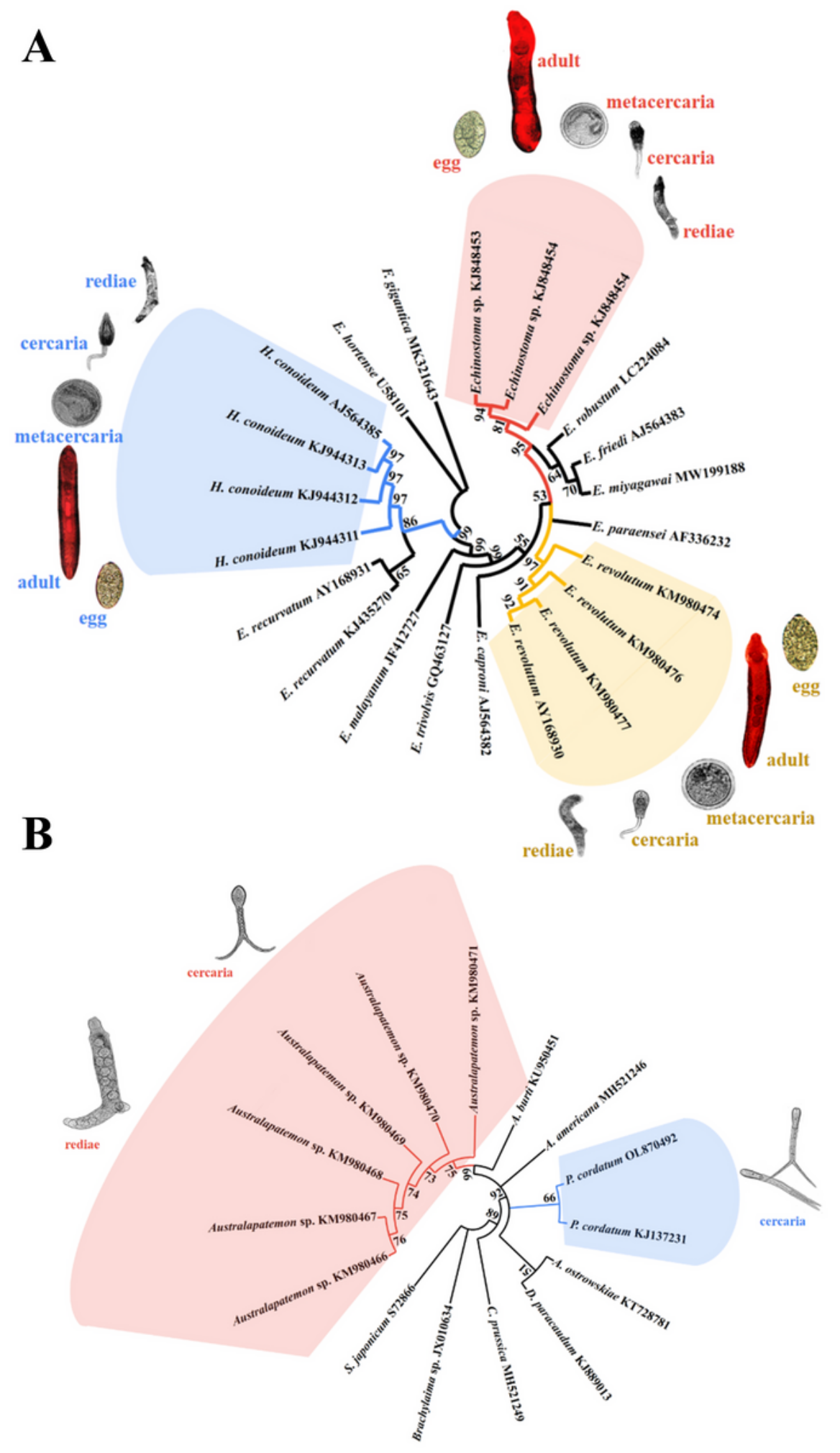

\section{Figure 3}

Phylogenetic analyses of isolated trematodes based on the ITS2 sequences and relevant GenBank sequences. A: Neighbor joining bootstrap consensus tree with 1000 bootstrap iterations for the rediae of echinostoms; B: Neighbor joining bootstrap consensus tree with 1000 bootstrap iterations for Australapatemon sp. and Pharyngostomum cordatum. 


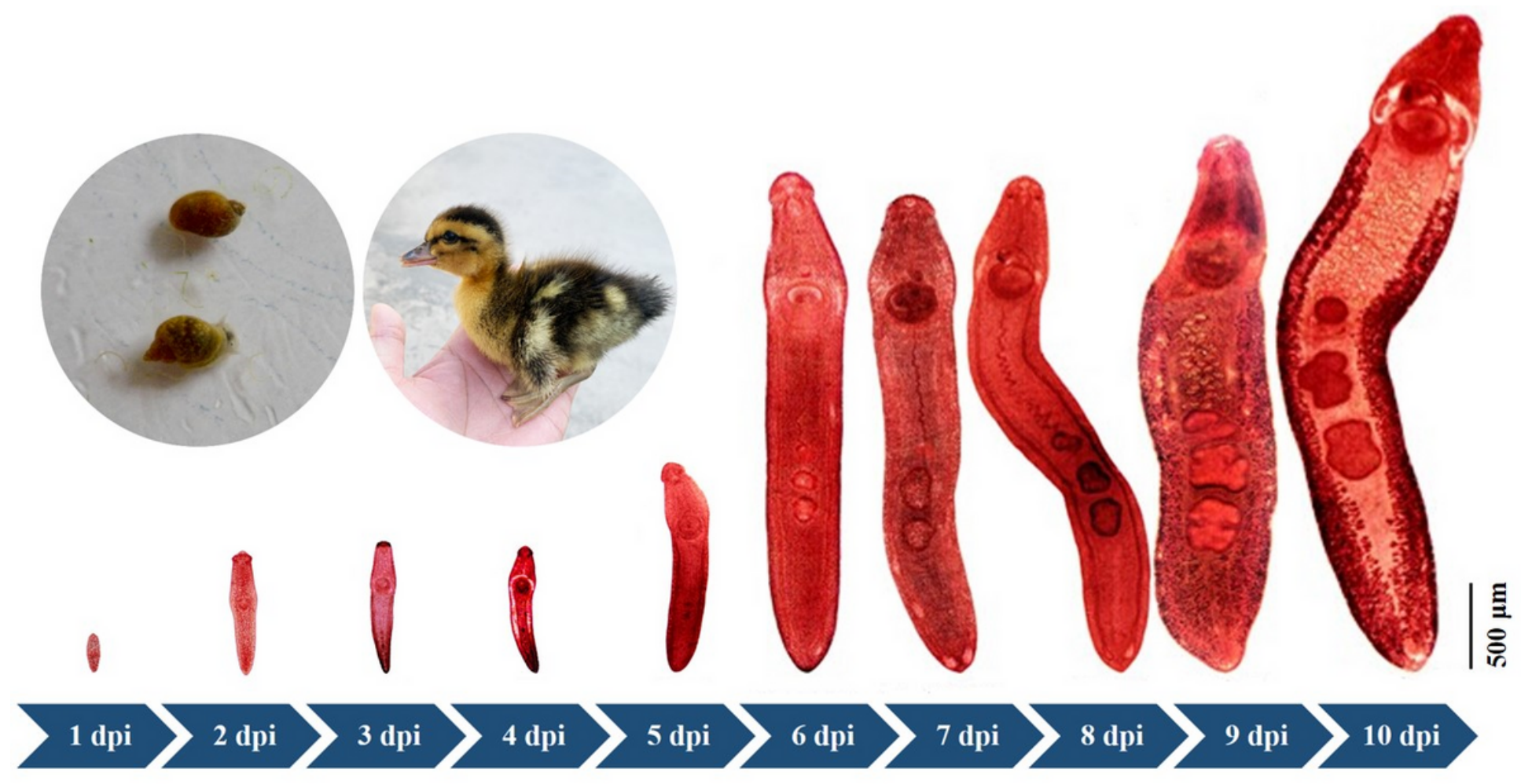

Figure 4

Development of E. revolutum in duckling host from $1 \mathrm{dpi}$ to $10 \mathrm{dpi}$

\section{Supplementary Files}

This is a list of supplementary files associated with this preprint. Click to download.

- TableS1.docx

- Tables2.docx 